\title{
Road Quality Assessment Using International Roughness Index Method and Accelerometer on Android
}

\author{
Eko Budi Setiawan ${ }^{\mathrm{a} 1}$, Hadi Nurdin ${ }^{\mathrm{a} 2}$ \\ ${ }^{a}$ Informatics Engineering, Universitas Komputer Indonesia \\ JI. Dipatiukur 112 Bandung, Indonesia \\ 1eko@email.unikom.ac.id \\ ²hadinurdin99@email.unikom.ac.id
}

\begin{abstract}
The quality of road conditions can determine comfort in driving. To find out the condition of a road whether it has good surface quality, it can use an accelerometer sensor contained in an android smartphone. This research uses the International Roughness Index (IRI) method combined with the accelerometer sensor and the Global Positioning System (GPS). Application of the results of this study can be used to facilitate the contractor maker and road repair, so they can find out which points need to be repaired. Testing is done using two different vehicles, car and motorcycle. Smartphones with road quality detection applications are attached to the car and motorcycle vehicles using a phone holder. This is to record vibration that occurs while the vehicle is moving based on road conditions. The vibration recording results are then validated in a visual observation to determine the accuracy of the assessment results. Based on the test results the level of accuracy on the car is $90 \%$ and the motorcycle is $30 \%$.
\end{abstract}

Keywords: Road Quality Assessment, International Roughness Index, Android, Accelerometer, GPS

\section{Introduction}

The existence of roads in each region is needed to support every community activity. Good road quality is needed to ensure the comfort and safety of vehicle users [1]. Poor road quality can cause accidents. Roads with holes besides making driving uncomfortable can also cause accidents [2].

To improve road quality, routine checks are required by those responsible for managing the road. Checking the road conditions can be done visually or by evaluating using a tool to assess the quality of road conditions can use the International Roughness Index (IRI) method and the pavement condition index.

In road quality assessments, researchers used the IRI as a road quality index. This assessment has been widely used for road infrastructure maintenance and road monitoring conditions since a long time [3] [4]. IRI can also be used to predict a pavement condition [5]. The IRI method is commonly used when assessing road conditions based on their inequality with a device. While the pavement condition index method is used when assessing road conditions based on its hardness [6].

The accelerometer and Global Positioning System (GPS) sensors on android can be used to assess road conditions. Research [7] has weaknesses related to data processing, road quality record results data only displayed graphically digital accelerometer still cannot be processed into table-shaped data. By assessing the shocks that occur on the Y-axis or vertical of the vehicle caused by holes or road bumps during the survey [8] [9]. 
To calculate IRI, an accelerometer sensor can also be implemented in a wheel [10]. The testing required laser profilometers that were expensive. The accelerometer sensor in an android smartphone can be used to minimize the costs needed when assessing road conditions. The accelerometer sensor on the smartphone can also use for speed bumping detection [11], fall detection [12] and real-time human activity detection [13].

GPS sensors are required to record the location of the detected road shocks. GPS sensors that will transmit the coordinate position when there is a considerable shock due to uneven road conditions. In the world of transportation, the use of GPS is widely used to track the position of a vehicle.

To study the effect of the characteristics of asphalt roads on the quality of driving, a precise calculation is needed to measure road quality conditions that can produce a comprehensive index as a parameter value for evaluating the quality of driving on asphalt roads using vehicles. The index underlying IRI was first used by the World Bank in 1986 [7].

The International Roughness Index is a road ruggedness parameter calculated from longitudinal measurements of road conditions with accumulated output from four-wheeled vehicles and divided by distance or length of road conditions using GPS location point data to produce a summary of inequality indexes with slope units.

The vehicles used to assess road quality are four-wheeled vehicles, because they have twodimensional angles that receive shocks on the $Y$ axis against road conditions compared to twowheeled vehicles. The smaller the IRI value, the better the quality of the road [14]. The IRI index parameter can be seen in Figure 1.

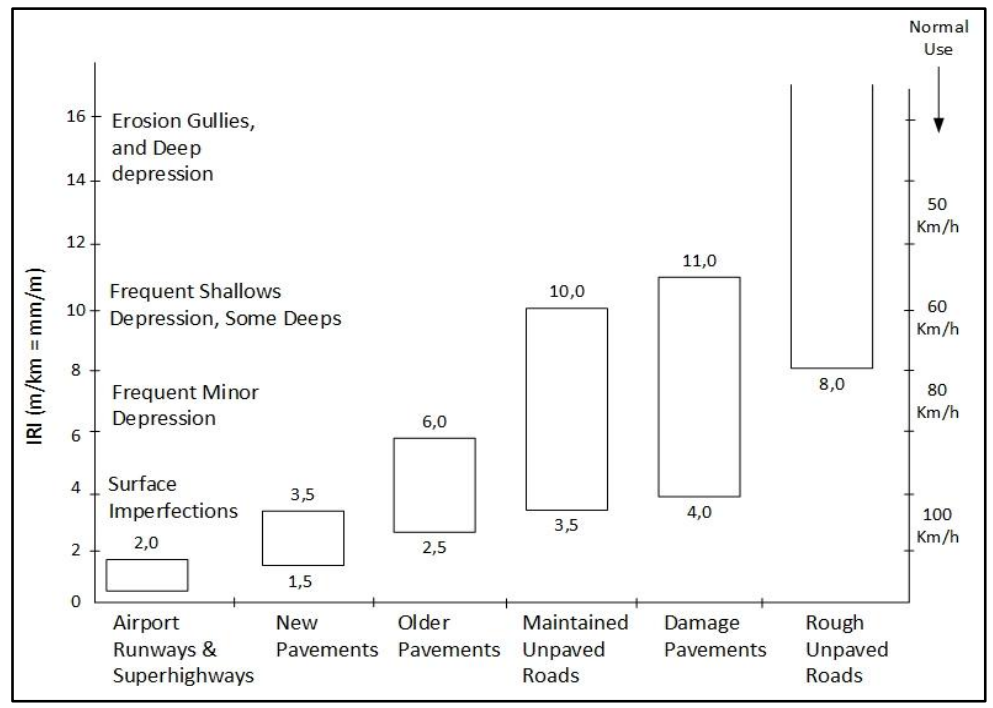

Figure 1. Scale of IRI parameter [15] [16] [17]

Based on Figure 1, the IRI value is influenced by the flatness of the road and the speed of the vehicle through it. The value of IRI 2,0 is the type of toll road quality and aircraft runway. Road quality with IRI value 2,0 is very good and can be used by vehicles up to speeds of more than $80 \mathrm{~km} / \mathrm{h}$. Road quality that has an IRI value of more than 2.0 due to uneven surfaces detected on the road, or the presence of a mound. This results when traversed by vehicles affect the level of vehicle speed across the road [18]. The worse the quality of the road results in the slower the speed of the vehicle.

This research aims to measure road quality by using an accelerometer sensor that is on an android smartphone using the International Roughness Index method. The road quality assessment process is carried out on public roads based on class I to class IIB which are types of asphalt and concrete roads [19] [20]. 


\section{Research Methods}

Methodology is part of epistemology or the science of knowing which can be said as the science of discovering. In connection with that, research methodologies need to see what they want to find in a particular theoretical framework so that what will be found gets its meaning [21]. Research methodology is a process that requires data to support research, each step is interrelated and connected to one another. The research flow steps carried out in this research can be seen in Figure 2.

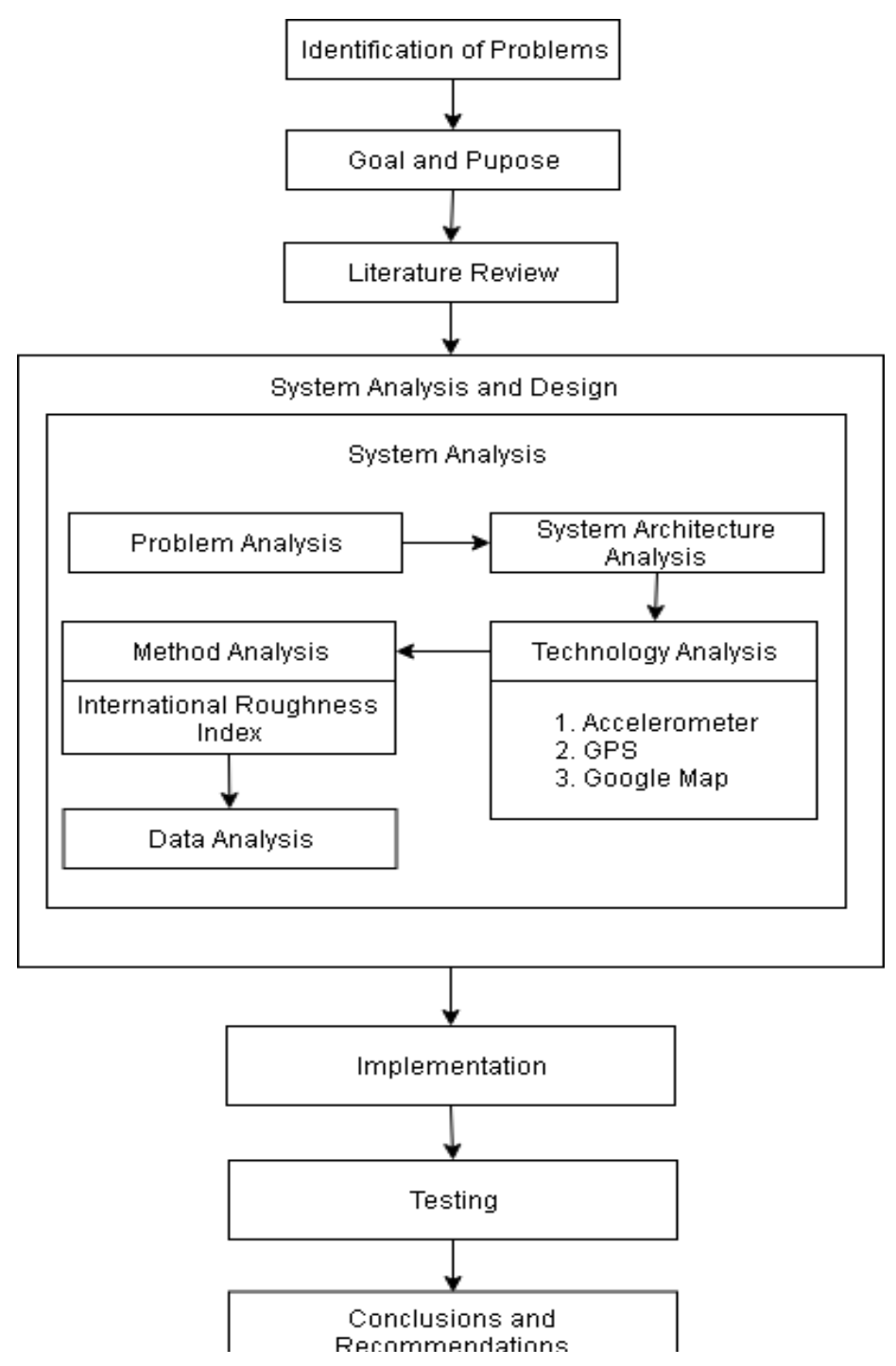

Figure 2. Stage of Research

\subsection{System Analysis and Design}

The system to be implemented is an application that detects road quality conditions using the accelerometer and GPS. System architecture is a general description of systems that work and are interrelated with one another. System users are surveyors, tasked with surveying road conditions by assessing road quality using applications, recording road conditions when the vehicle is running. Next is the system architecture can be seen in Figure 3. 


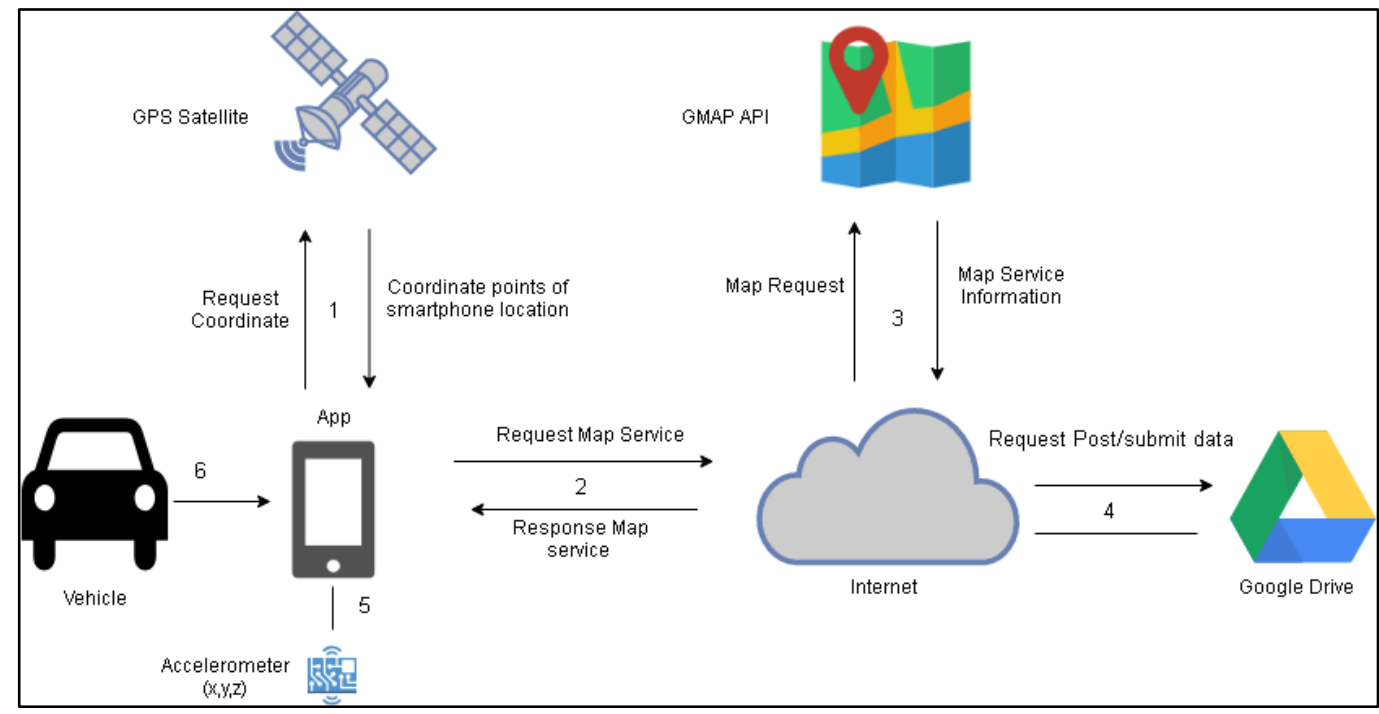

Figure 3. System Architecture

Information related to the image above is as follow.

1. The android device asks for smartphone coordinates, GPS satellite gives the position of smartphone coordinates.

2. The android devices enter the internet network

3. The android devices request map services, Google Maps API provides service maps

4. The device exports data to the Google Drive storage media

5. The application detects vibrations that occur while the vehicle is running

6. The device is in a vehicle

\subsection{Technology Used}

Analysis of technology used is a process of analysis of the workings of the technologies that will be used by the system. In this research there are several technologies that will be explained which consist of an analysis of how the accelerometer sensor works in detecting road quality conditions by processing shock data or bumps recorded by the application.

\subsubsection{Accelerometer}

Smartphone currently generally has an accelerometer sensor for various needs such as changing the screen display from portrait to landscape or vice versa by tilting the cellphone body, this occurs because there is a change in the $x, y, z$ value of a smartphone, the accelerometer axis value can be seen in Table 1.

Table 1. Accelerometer Axis Value

\begin{tabular}{lccc}
\hline Position & $\mathrm{x}$ & $\mathrm{y}$ & $\mathrm{z}$ \\
\hline vertical & 0 & 1 & 0 \\
vertical upside down & 0 & -1 & 0 \\
right landscape & 1 & 0 & 0 \\
left landscape & -1 & 0 & 0 \\
flat & 0 & 0 & 1 \\
flat upside down & 0 & 0 & -1 \\
\hline
\end{tabular}

The calculation of the accelerometer value will be focused on the y axis, because the position of the smartphone when recording data is vertical. The accelerometer sensor will record longitudinal waves or vibrations along with the vehicle's mileage. Figure 4 illustrates that the $t_{i}$ constant is a sample of time, and the $h_{i}$ constant is a longitudinal road surface. 


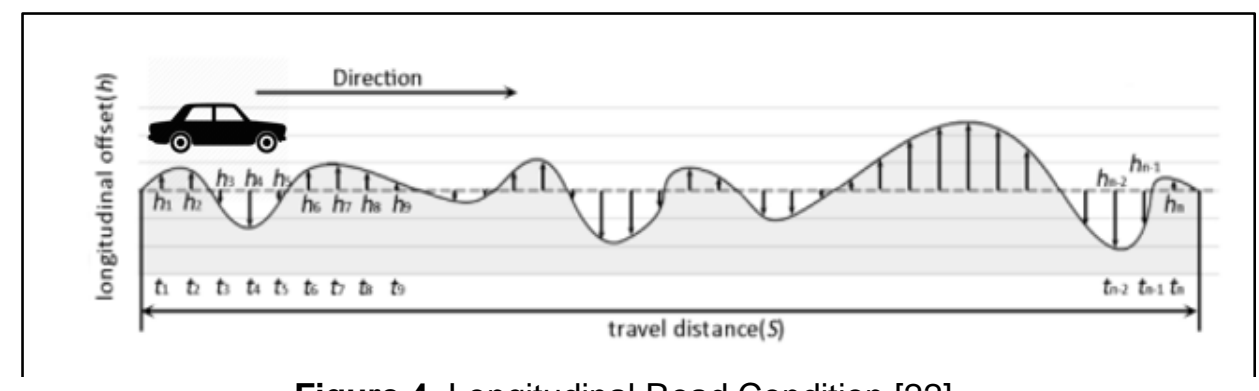

Figure 4. Longitudinal Road Condition [22]

Through calculations, the results of the vertical displacement value (Vhi) of each interval sampling can be obtained in Figure 5 and Table 2:

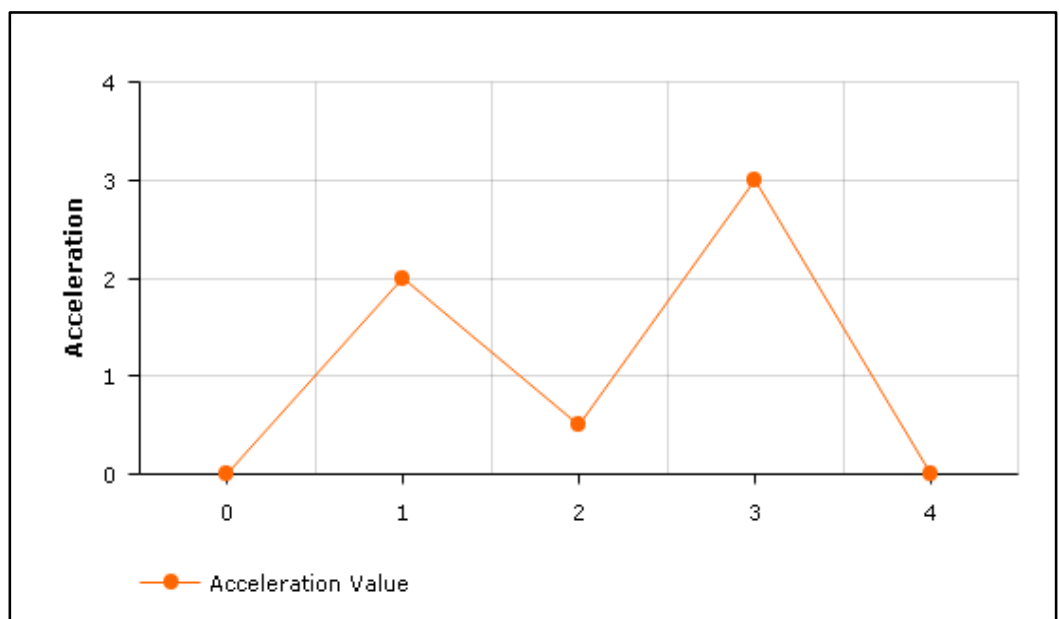

Figure 5. Example of a longitudinal accelerometer condition

Table 2. Acceleration value on the accelerometer

\begin{tabular}{cc}
\hline Time $(\mathrm{t})$ & Acceleration value $(\mathrm{A})$ \\
\hline 0 & 0 \\
1 & 2 \\
2 & 0.5 \\
3 & 0 \\
\hline
\end{tabular}

With acceleration data $(\mathrm{A})$ and time $(\mathrm{t})$ obtained from accelerator, calculations are made to integrate the acceleration values that occur.

$A=$ Acceleration

$\mathrm{V}=$ Speed

$\mathrm{P}=$ Position

$\mathrm{t}=$ unit time seconds

$V_{\mathrm{i}}=$ vertical displacement per second

By Formula,

$$
\begin{aligned}
& V=V+A d t \\
& P=P+V d t
\end{aligned}
$$

With the example above, it can be described as follows to integrate the accelerometer value.

$$
\begin{aligned}
& V_{1}=0, \\
& V_{2}=V_{1}+\frac{A_{1}+A_{2}}{2}\left(t_{2}-t_{1}\right) \\
& V_{2}=0+\frac{0+2}{2}(1-0) \\
& V_{2}=1
\end{aligned}
$$




$$
\begin{aligned}
& P_{1}=0, P_{2}=P_{1}+\frac{V_{1}+V_{2}}{2}\left(t_{2}-t_{1}\right) \\
& P_{2}=0+\frac{0+1}{2}(1-0) \\
& P_{2}=0.5 \\
& V_{2}=1, \\
& V_{3}=V_{2}+\frac{A_{2}+A_{3}}{2}\left(t_{3}-t_{2}\right) \\
& V_{3}=1+\frac{1+0.5}{2}(2-1) \\
& V_{3}=1.75(2) \\
& V_{3}=3.5 \\
& P_{3}=P_{2}+\frac{V_{2}+V_{3}}{2}\left(t_{3}-t_{2}\right) \\
& P_{3}=0.5+\frac{1+3.5}{2}(2-1) \\
& P_{3}=2.75(2) \\
& P_{3}=5.5 \\
& \bar{V}=\frac{0+1+3.5}{3} \\
& \bar{V}=1,5 \mathrm{~m} / \mathrm{s} \\
& \bar{P}=\frac{0+0.5+5.5}{3} \\
& \bar{P}=2 \\
& V h i=\bar{V} * \bar{P} \\
& V h i=1,5 * 2 \\
& V h i=3
\end{aligned}
$$

\subsubsection{Road Quality Assessment Methods}

Based on IRI's explanation, the sum of all sampling intervals, then divided by the value of the distance (S) with the count [22].

$$
I R I=\frac{\sum_{i=2}^{n} V h_{i}}{S}=\frac{\sum_{i=2}^{n}\left|h_{i}-h_{i-1}\right|}{S}
$$

When calculating IRI, it takes the total distance traveled (S) and the result of the vertical accelerometer transfer to each sampling time. Mileage can be calculated via GPS. However, vertical displacement is not a value that can be obtained directly and derived from the results of the accelerometer sensor, in known physics formulas:

$$
\begin{gathered}
V v=\frac{d V h}{d t} \\
\alpha v=\frac{d V v}{d t}=\frac{d^{2} V h}{d t^{2}}
\end{gathered}
$$

Where $t$ is time, $V v$ is vertical speed, $\alpha v$ is vertical acceleration, and $V h$ is vertical displacement. Then:

$$
\sum V h=\iint_{t_{\text {first }}}^{t_{\text {end }}}\left|\alpha_{v}\right|\left(d t^{2}\right)
$$

By adding the distance traveled, the above formula can be summarized as follows:

$$
I R I=\frac{\sum_{i=2}^{n} V h i}{S}=\frac{\iint_{t_{\text {first }}}^{e_{\text {end }}}\left|\alpha_{v}\right|\left(d t^{2}\right)}{S}
$$




\subsubsection{Obtain IRI from Accelerometer and GPS}

a. Calculate distance traveled

Distance can be calculated using the speed of travel time to point one to colon using GPS. By formula:

$$
S=\int_{0}^{t} V_{t} d t
$$

$V_{t}$ is the travel speed measured at time t, can be obtained directly from the GPS sensor.

b. Obtaining Vertical Transfer Value

The acceleration of vertical movements can be recorded using an accelerometer sensor on a smartphone, which gives more data sampling. Vertical acceleration (av) can appear in the dimensions of the three axes especially the $y$-axis, acceleration data is generated by the accelerometer, in other words, the $y$-axis acceleration data from the accelerometer cannot be taken directly as vertical acceleration data requires a method to obtain av from the acceleration value all three axes.

In the process of collecting data, when a user starts recording data, the vehicle must be in a normal or stable position. The style received by the smartphone (accelerometer) is only one gravitational force, vertical and downward direction with a value of (2) by formula [22]:

$$
\bar{A} x * \bar{A} x+\bar{A} y * \bar{A} y+\bar{A} z * \bar{A} z=1
$$

$\bar{A} x, \bar{A} y, \bar{A} z$ is the average acceleration value of the $\mathrm{x}, \mathrm{y}$, and $\mathrm{z}$ axes in every 5 seconds, obtained from the smartphone accelerometer sensor.

Obtain vertical acceleration (av) from each axis, value $\mathrm{A}=\left(A_{x}, A_{y}, A_{z}\right)$ can be interpreted as projection of vector $\mathrm{A}$, with vector references $\bar{A}=(\bar{A} x, \bar{A} y, \bar{A} z)$, measurement at the beginning of the data collection process, in other words, $\alpha \mathrm{v}$ is a scalar projection of vector $\mathrm{A}$ and $\bar{A}$, then the formula can be obtained as follows [22] :

$$
A v=\frac{A \cdot \bar{A}}{\overline{|A|} \mid}=\frac{A x * \overline{A x}+A y * \bar{A} y+A z * \bar{A} z}{\sqrt{\bar{A} x * \overline{A x}+\bar{A} y * \bar{A} y+\bar{A} z * \bar{A} z}}=A x * \overline{A x}+A y * \bar{A} y+A z * \bar{A} z
$$

\section{Result and Discussion}

At this stage consists of the result of implementation.

\subsection{System Implementation}

System implementation is the stage of translating the design at the analysis stage. The hardware specification used to use the system and the minimum hardware requirements needed to run the system that is using snapdragon 625 processor, 13 MP camera, 3 GB RAM, 16 GB ROM, the smartphone has an accelerometer sensor and an android 4.4 KitKat operating system.

\subsubsection{Application Implementation}

Application implementation explains the interface implementation of an android application. Implementation of the interface can be seen in Figure 5. 


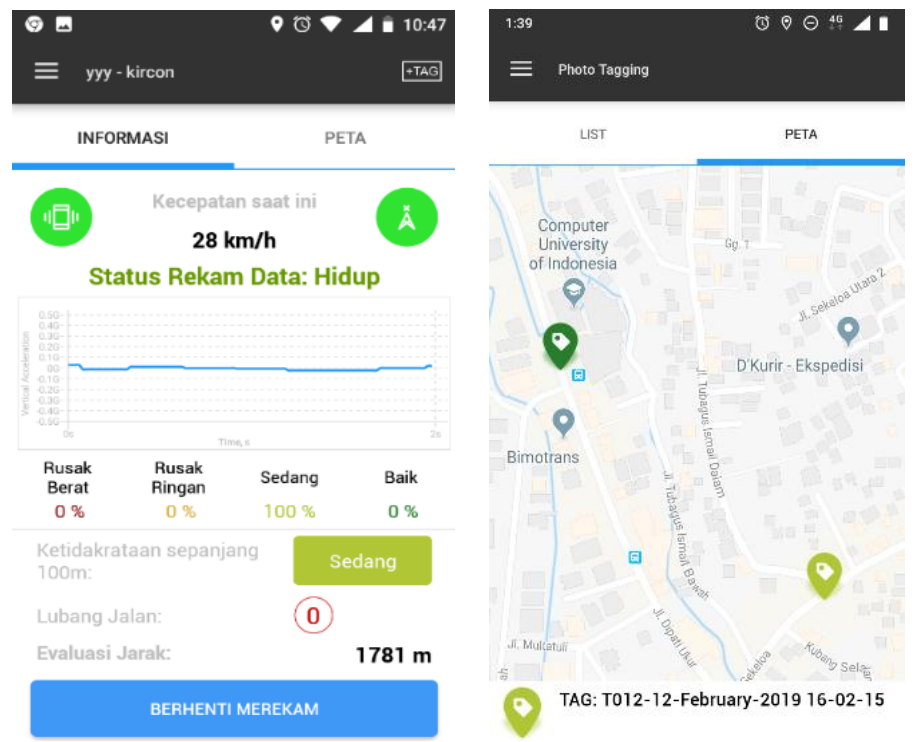

Figure 2. Application Interface Implementation

Figure 5 is the appearance of an android application to record road quality conditions, the system will continue to record road conditions as long as the vehicle is running included accelerometer charts, the graph will react if there is a shock or detected a hollow road, in Figure 5 the graph looks stable and does not rise shock or potholes are detected.
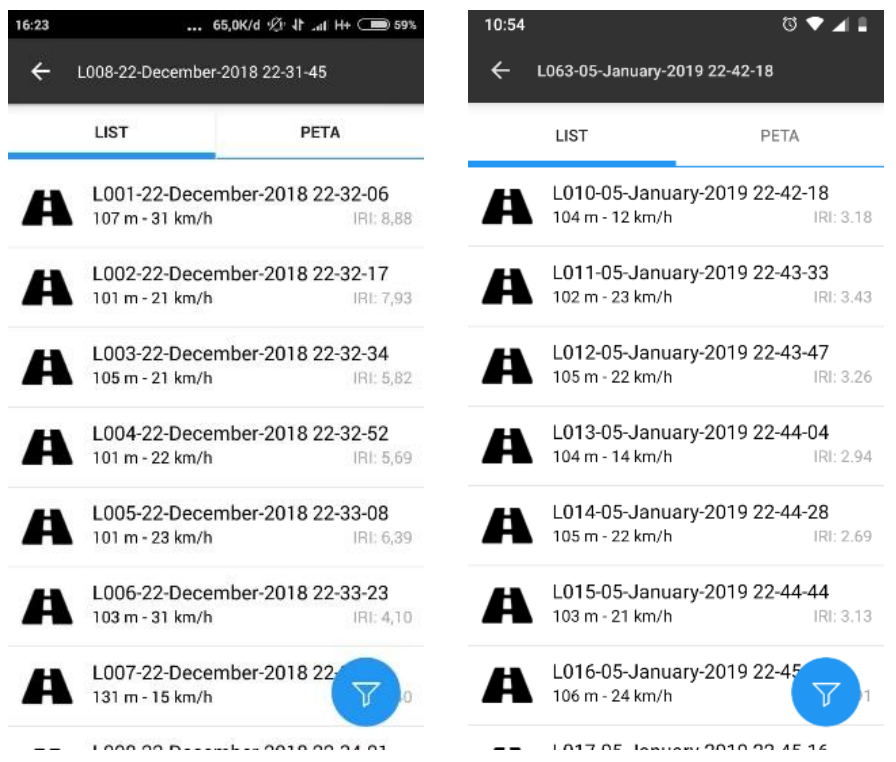

Figure 3. Road Quality Record Data Implementation

The interface display in Figure 6 is the result of road quality record data along the distance traveled during the road quality record process. Road quality record data has an interval of 100 meters to do IRI calculations so that the collected data is calculated as the IRI average value

\subsubsection{Accuracy of Road Quality Assessment}

The application testing was conducted on January 5, 2019, using the Daihatsu Ayla car and the Yamaha Mio's motorcycle. This test was carried out in the city of Bandung, the starting point was at Cikutra Park street the tomb of the hero to the endpoint of Tubagus ismail street. The International Roughness Index road quality calculation is carried out every distance of 100 meters and then the International Roughness Index is calculated from the overall distance. 
Figure 7 is a display when the application is tested using the Daihatsu Ayla car vehicle. The testing route can be seen in Figure 8.
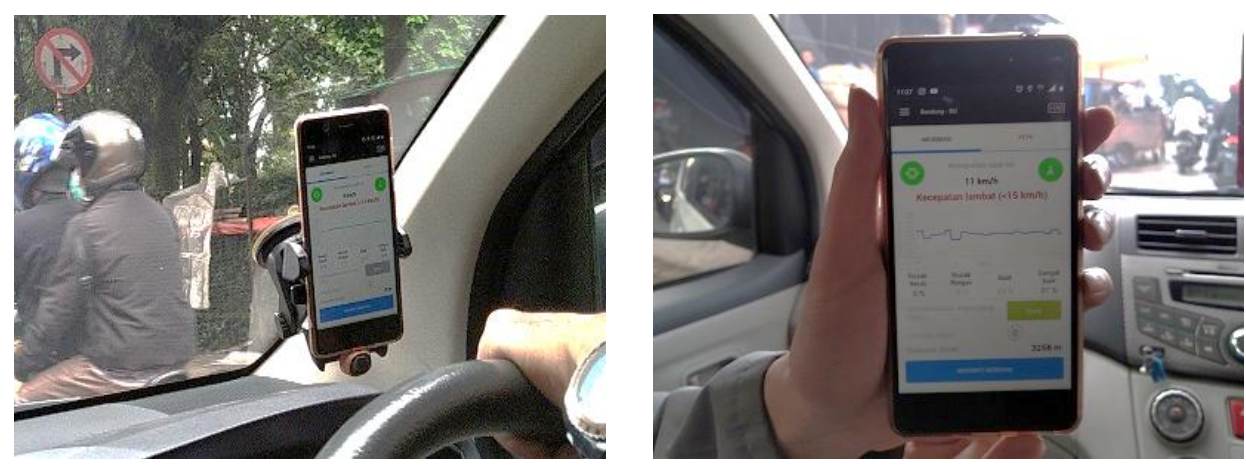

Figure 7. Application testing

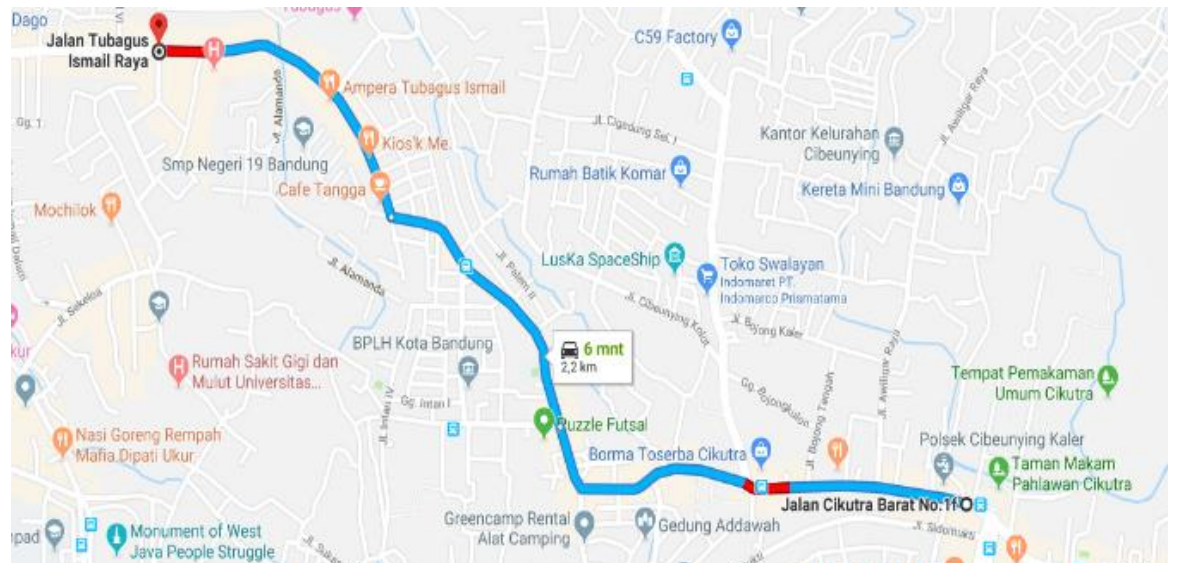

Figure 8. Testing Route

In addition to testing with the application system, visual testing is also carried out by looking directly at the physical condition of the road detected by the system by what is seen by the vision and vibration felt by the testers so that the system testing can be assessed for the accuracy of manual assessment by human vision.

The following is the output data generated during the test can be seen in Table 3 and Table 4.

Table 3. Road Quality Record Data on The Car

\begin{tabular}{crcrrc}
\hline No & Speed km/h & Category & IRI & Distance & Visual \\
\hline 1 & 11.82 & Good & 3.18 & 104.07 & Valid \\
2 & 22.7 & Good & 3.43 & 101.58 & Invalid \\
3 & 22.05 & Good & 3.26 & 104.51 & Valid \\
4 & 13.52 & Good & 2.94 & 103.93 & Valid \\
5 & 22.49 & Good & 2.69 & 104.91 & Valid \\
6 & 21.28 & Good & 3.13 & 103.14 & Valid \\
7 & 23.72 & Good & 2.91 & 105.75 & Valid \\
8 & 24.53 & Good & 2.87 & 106.98 & Valid \\
9 & 30.32 & Good & 2.3 & 101.48 & Valid \\
10 & 27.7 & Good & 2.79 & 104.21 & Valid \\
\hline
\end{tabular}


Table 4. Road Quality Record Data on The Motorcycle

\begin{tabular}{crcrrc}
\hline No & Speed km/h & Category & IRI & Distance & Visual \\
\hline 1 & 31.39 & Poor & 8.88 & 106.94 & Invalid \\
2 & 20.57 & Fair & 7.93 & 101.36 & Invalid \\
3 & 20.75 & Fair & 5.82 & 105.4 & Valid \\
4 & 22.12 & Fair & 5.69 & 101.16 & Valid \\
5 & 23.07 & Poor & 6.39 & 101.07 & Invalid \\
6 & 31.29 & Fair & 4.1 & 103.3 & Invalid \\
7 & 14.55 & Fair & 4.4 & 130.53 & Invalid \\
8 & 18.64 & Good & 3.57 & 101.58 & Valid \\
9 & 17.74 & Fair & 5.23 & 121.02 & Valid \\
10 & 27.75 & Fair & 5.31 & 103.63 & valid \\
\hline
\end{tabular}

Referring to research [23] and [24], the categories in table 3 and table 4 are said to be good if the IRI value is less than 4 , the fair category has an IRI value of 4 to 8 , a poor category with IRI 8 to 12. Research conducted by Tho'atin assess road conditions are also using IRI, but the studies were not conducted a visual comparison to the validation results of the assessment of road conditions.

IRI value using car:

$$
\begin{aligned}
& \text { IRI }=\sum \text { iri } / 10 \\
& \text { IRI }=29.5 / 10 \\
& \text { IRI }=2.95
\end{aligned}
$$

IRI value using motorcycle:

$$
\begin{aligned}
& \text { IRI }=\sum \text { iri } / 10 \\
& \text { IRI }=57.32 / 10 \\
& \text { IRI }=5.73
\end{aligned}
$$

From testing result on table 3 and table 4, the car has 9 valid data out of a total of 10 data, so the accuracy of the application using the car can be calculated as follows:

$$
\frac{9}{10} \times 100=90 \%
$$

Motorcycle have valid data 6 out of a total of 19 data, so the accuracy of the use of applications with motorcycle can be calculated as follows:

$$
\frac{3}{10} \times 100=30 \%
$$

Motorcycle uses a suspension that is not too good when compared to a car suspension. This makes the test using a motorcycle, resulting in a value of accuracy that is not too good when compared with the results of visual observations.

The following is a graph of the test results on car and motorcycle vehicles in Figure 9. 


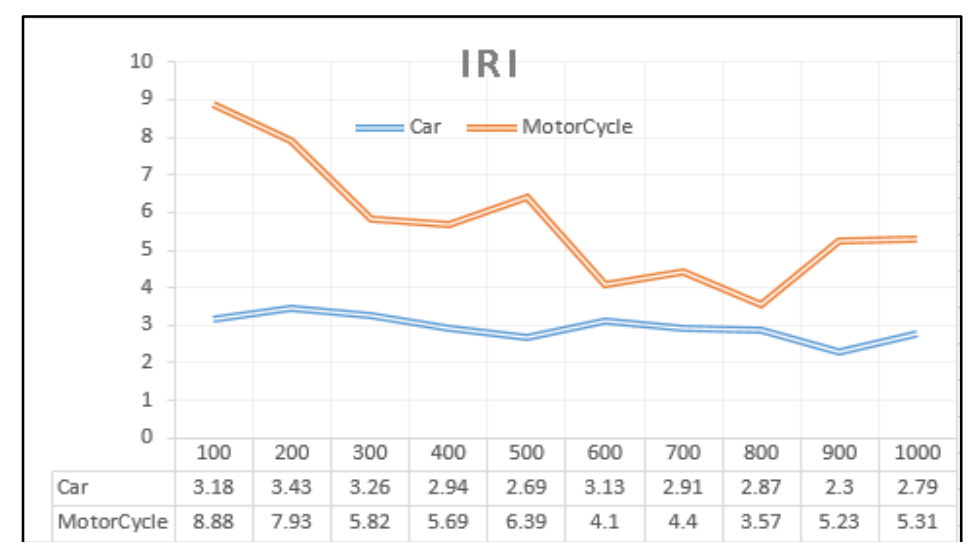

Figure 9. IRI Assessment Chart

Based on figure 9 the graph of road quality assessment on cars with blue lines shows a lower and stable IRI value with numbers 2 and 3 . While the assessment of road quality on a motorcycle with an orange line color shows IRI values which tend to be larger and unstable, this shows a low level of accuracy compared to car vehicles.

The level of accuracy of the test results using a car has a higher value than the results of testing using a motorcycle. This is because the car has a suspension that is better than a motorcycle. The car also has four suspensions, thus affecting the stability of the system in detecting vibration. That is because the smartphone device when testing is placed in the middle of the four suspensions in the car.

\section{Conclusion}

The conclusions and suggestions obtained from the results of this research are android smartphones that have an accelerometer sensor can be used to determine the quality of the highway using the International Roughness Index (IRI) method. The level of accuracy of the results obtained when using a car produces a more stable value and is more accurate when compared to when testing using a motorcycle. This is due to several factors, one of which is because the car's suspension is softer than a motorcycle. The car also has a greater number of suspensions than the motorcycle, so that it can reduce the vibrations that occur.

\section{References}

[1] Sattar, S., Li, S. and Chapman, M, "Road surface monitoring using smartphone sensors: A review" Sensors, vol. 18 no. 11, pp.3845. 2018.

[2] F. Suwarto and A. Nugroho, "Audit Keselamatan Jalan Sebagai Dasar Implementasi Perencanaan Karakteristik jalan” Jurnal Proyek Teknik Sipil, vol. 2 no. 1, pp. 22, 2019.

[3] Mahajan and D. V, "Estimation of Road Roughness Condition by Using Sensors in Smartphone" International Journal of Computer Engineering and Technology, vol. 6, no. 7, p. 9, 2015.

[4] Harshgandha, P. Matale, N. Bidgar and SnehaKatkade, "Roadside Quality And Ghat Complexity Analysis", International Journal of Advanced Information and Communication Technology, vol. 1, no. 11, pp. 5, 2015.

[5] S. A. Arhin, L.N. Williams, A. Ribbiosi and M. F. Anderson. "Predicting Pavement Condition Index Using International Roughness Index in a Dense Urban Area", Journal of Civil Engineering Research, vol.5 no.1, pp. 10, 2015.

[6] D. A. Putra and M. Suprapto, "Assessment of the road based on PCI and IRI roadroid measurement", in International Conference on Rehabilitation and Maintenance in Civil Engineering (ICRMCE 2018), pp.1-8, vol. 195, 2018.

[7] Chenglong, Difei and Yuchuan, "Measurement of International Roughness Index by using Z-Axis Accelerometers and GPS", Mathematical Problems in Engineering Journal, vol.2014, pp. 10, 2014. 
[8] B.U. Lanjewar, R.Sagar, R. Pawar, "Road Bum and Intensity Detection using Smartphone Sensors," International Journal of Innovative Research in Computer and Communication Engineering, vol. 4, no. 5, pp. 8, 2016.

[9] Yehezkiel, Otniel "Rancang Bangun Sistem Pendeteksi Bump Menggunakan Android Smartphone dengan Sensor Akselerometer," Jurnal Teknik ITS, vol. 5, no. 2, p. 6, 2016.

[10] Y. Zhao and M. L. Wang, "IRI Measurement Using Dynamic Tire Pressure Sensor With an Axle Accelerometer", Journal of Civil Structural Health Monitoring", vol.6, no.5. pp.791, 2016.

[11] A. Aljaafreh, K. Alawasa, S. Alja'afreh, "Fuzzy Inference System for Speed Bumps Detection Using Smart Phone Accelerometer Sensor", Journal of Telecommunication, Electronic and Computer Engineering (JTEC), vol. 9. No. 2, pp.133, 2017.

[12] B. Kwolek and M. Kepski, M, "Fuzzy inference-based fall detection using kinect and body-worn accelerometer", Journal of Applied Soft Computing, vol. 40, p.305, 2016.

[13] A. Ignatov. ""Real-time human activity recognition from accelerometer data using Convolutional Neural Networks.", Journal of Applied Soft Computing, vol. 62, pp.915, 2018.

[14] Eshkabilov and A.G Yusunov, "Measuring and Assessing Road Profile by Employing Accelerometers and IRI Assesment Tools", American Journal of Traffic and Transportation Engineering, vol. 3, no.2, pp. 10, 2018.

[15] Greene S, Akbarian M, Ulm FJ, Gregory J, "Pavement roughness and fuel consumption", Concrete Sustainability Hub, Massachusetts Institute of Technology, 2013.

[16] Qiao F, Li Q, Yu L, How the Roadway Pavement Roughness Impacts Vehicle Emissions? Environ Pollut Climate Change 1:134. 10.4172/2573- 458X.1000134, 2017.

[17] M R Schlotjes, A Visser, C Bennet, Evaluation of A Smartphone Roughness Meter, in Proceedings of the 33rd Southern African Transport Conference (SATC 2014), 2014.

[18] Arianto, T., and M. Suprapto. "Pavement Condition Assessment Using IRI from Roadroid and Surface Distress Index Method on National Road in Sumenep Regency." In IOP Conference Series: Materials Science and Engineering. Vol. 333. No. 1. IOP Publishing, 2018

[19] “Peraturan Pemerintah Republik Indonesia Nomor 34", 2006.

[20] "Peraturan Menteri Pekerjaan Umum No. 13", 2011.

[21] P. Setyosari, Metodologi Penelitian Pendidikan \& Pengembangan, Jakarta: Prenada Media Grup (Kencana), 2016.

[22] K. Zang, K., Shen, J., Huang, H., Wan, M. and Shi, J, "Assessing and mapping of road surface roughness based on GPS and accelerometer sensors on bicycle-mounted smartphones", Sensors, vol. 18, no.3, pp.914, 2018.

[23] Tho'atin, U., Setyawan, A., \& Suprapto, M, "Penggunaan Metode International Roughness Index (Iri), Surface Distress Index (Sdi) dan Pavement Condition Index (Pci) Untuk Penilaian Kondisi Jalan Di Kabupaten Wonogiri". In Proceedings of Seminar Nasional Sains dan Teknologi, 2016.

[24] A. Yuliani, S. Bahri, Y. Afrizal, "Analisis Tingkat Ketidakrataan Jalan Nasional Dengan Menggunakan Alat Naasra”, Jurnal Inersia”, vol. 10, no.2, pp.15, 2018. 